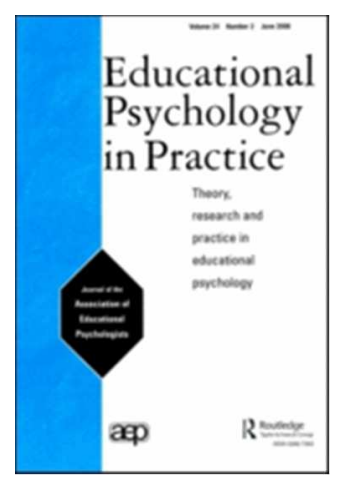

\title{
Building Secure Attachments for Primary School Children: A mixed methods study
}

\begin{tabular}{|r|l|}
\hline Journal: & Educational Psychology in Practice \\
\hline Manuscript ID: & Draft \\
\hline Manuscript Type: & Research \\
\hline Keywords: & $\begin{array}{l}\text { Attachment, Primary School Children, Mixed Methods, Secure base, } \\
\text { Childrens Drawings }\end{array}$ \\
\hline \multicolumn{2}{|l}{} \\
\hline
\end{tabular}

SCHOLARONE $^{m}$

Manuscripts 
Figure 1: The Structure of the Secure Friendships Group

Greetings song in circle

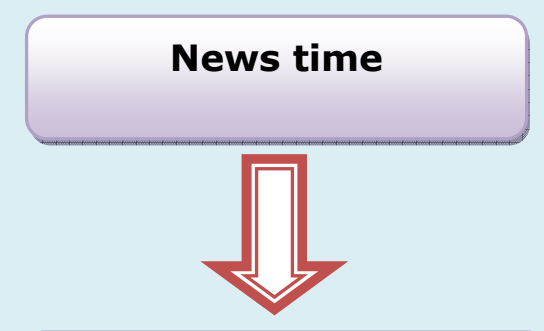

\section{Story telling}

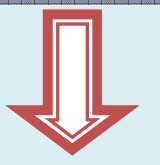

\section{Drawings/thought writing}

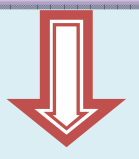

Processing and Reflecting

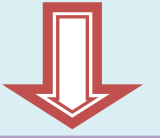

Closing Activities

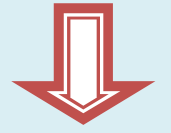

Good bye song in circle 
Figure 2: Children's total strengths and difficulties scores pre, post and follow-up to the secure friendships intervention group

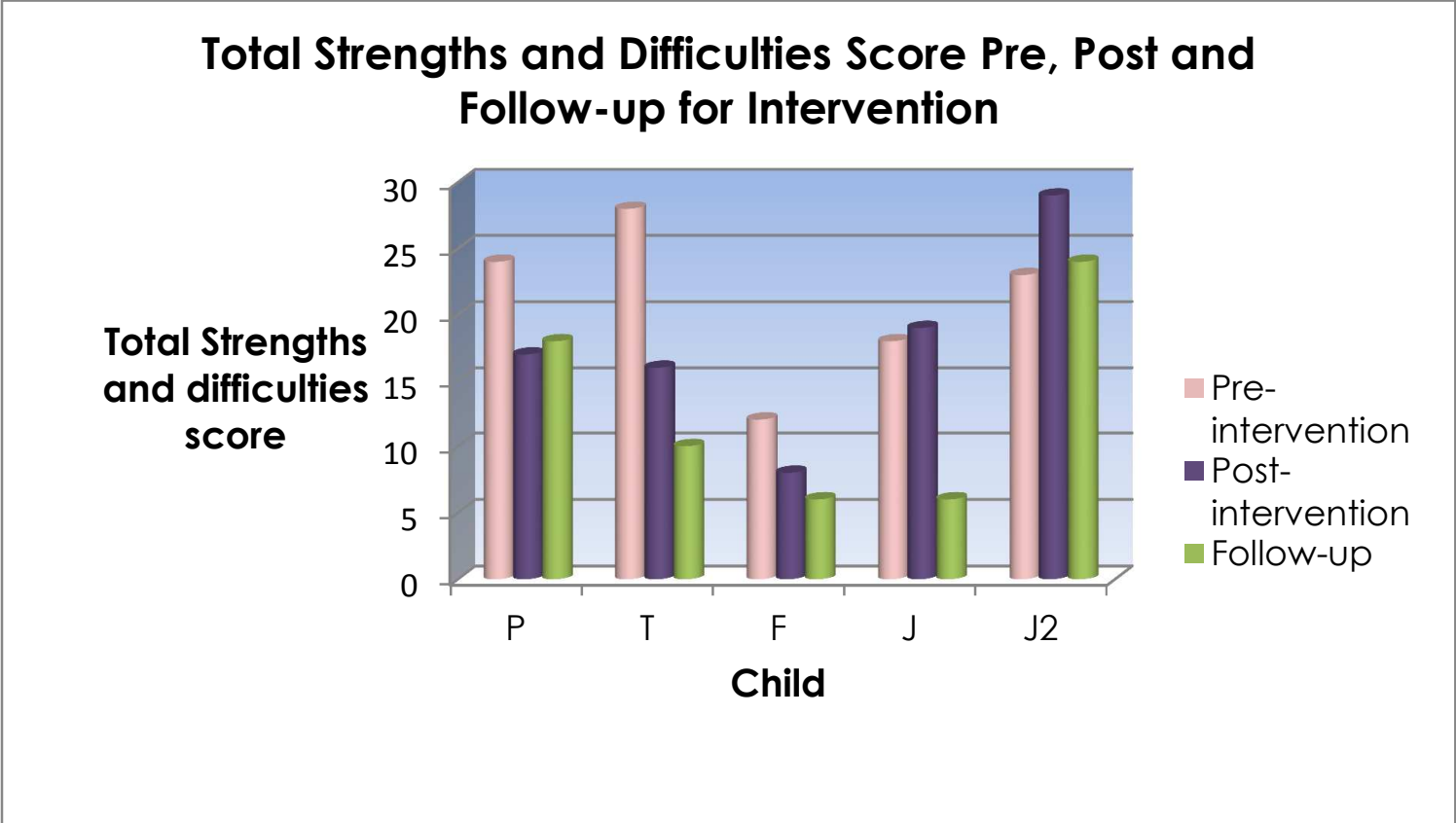

The borderline banding scores for each corresponding scale is indicated following each chart. Scores above this figure are abnormal, whilst scores below are normal.

Borderline score: 16-19 
Figure 3: Children's individual scores on the BIOS pre, post and followup to the secure friendships intervention group

Behavioural Indicators of Self-esteem (BIOS) Scores pre, post and follow-up to secure friendships group intervention

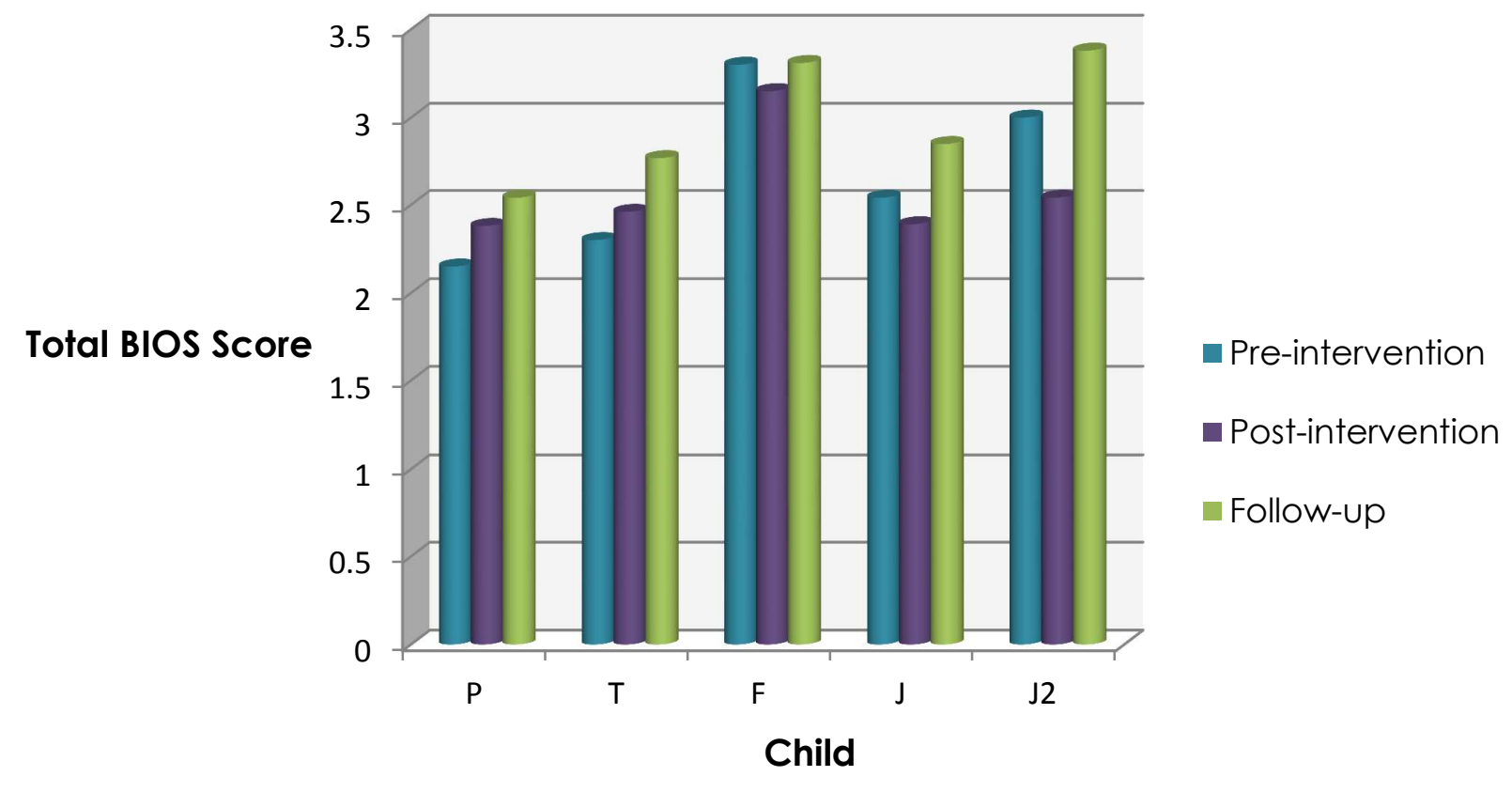

\begin{tabular}{|c|c|c|c|c|}
\hline \multicolumn{5}{|c|}{ BIOS Score for } \\
Self -esteem \\
\hline Very high & High & Average & Low & $\begin{array}{l}\text { Very } \\
\text { Low }\end{array}$ \\
& & & & $1-1.5$ \\
\hline $4.5-5$ & $3.5-4.5$ & $2.5-3.5$ & $1.5-2.5$ & $1-1.5$ \\
\hline
\end{tabular}

Profiles of Behaviour based on Attachment behaviour characteristics pre and post intervention 
Figure 4: Children's individual scores on the Profiles of Behaviour based on Attachment behaviour characteristics pre and post intervention

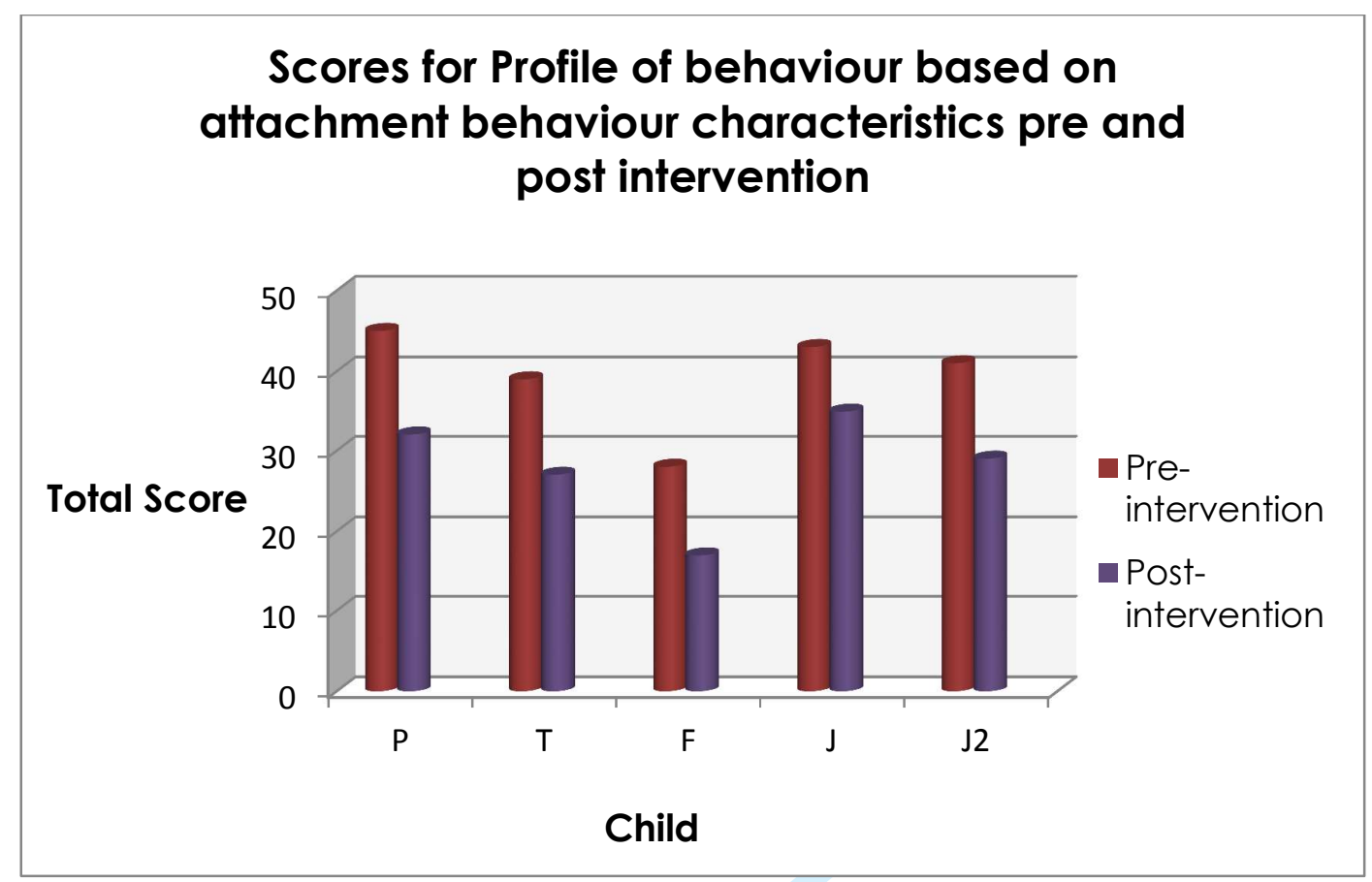


Figure 5: Child P pre-intervention Kinetic Family Drawing

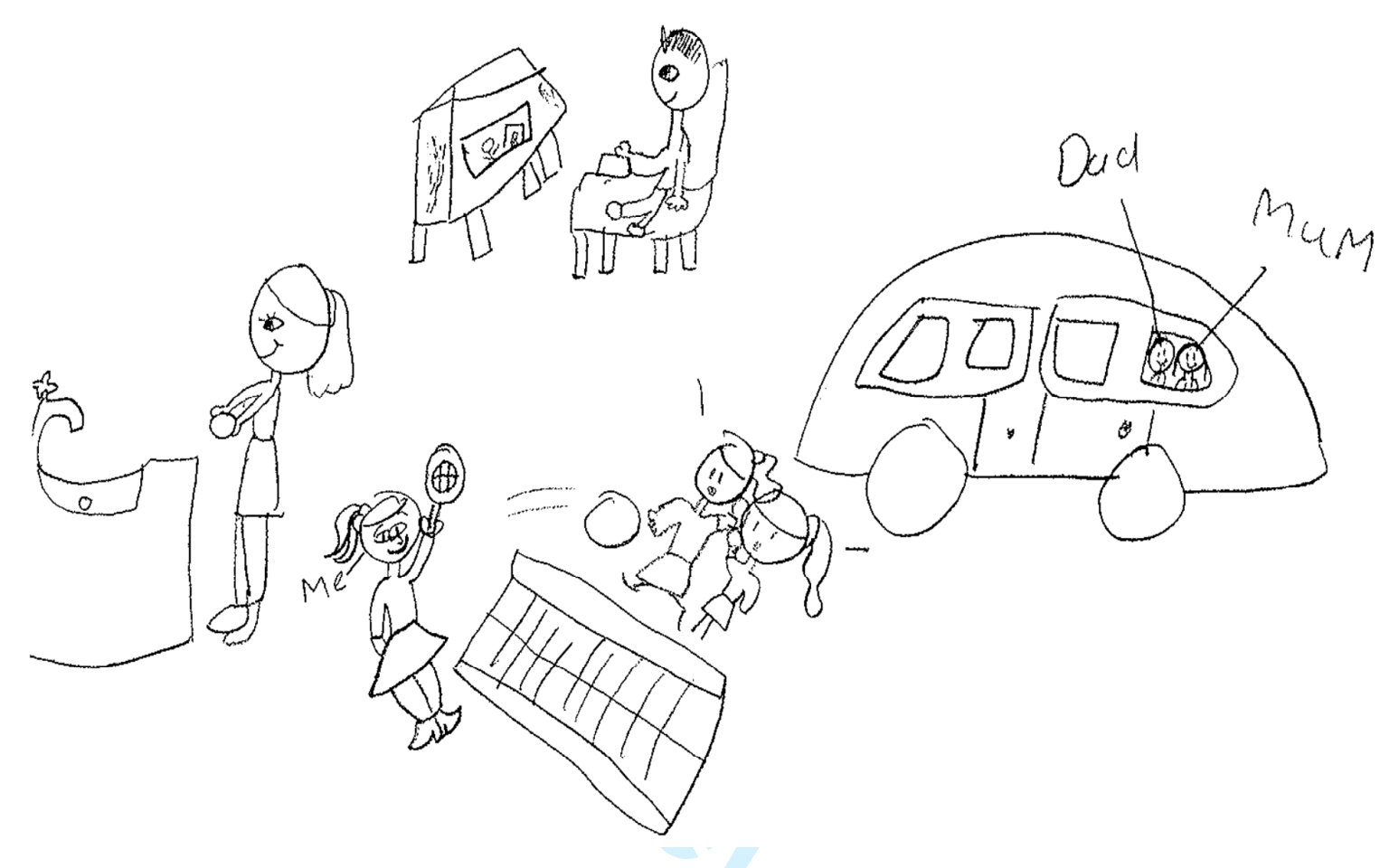

URL: http://mc.manuscriptcentral.com/epp 
Educational Psychology in Practice

Page 6 of 31

1
2
3
4
5
6
7
8
9
10
11
12
13
14
15
16
17
18
19
20
21
22
23
24
25
26
27
28
29
30
31
32
33
34
35
36
37
38
39
40
41
42
43
44
45
46
47
48
49
50
51
52
53
54
55
56
57
58
59
60

Figure 6: Child P post-intervention Kinetic Family Drawing

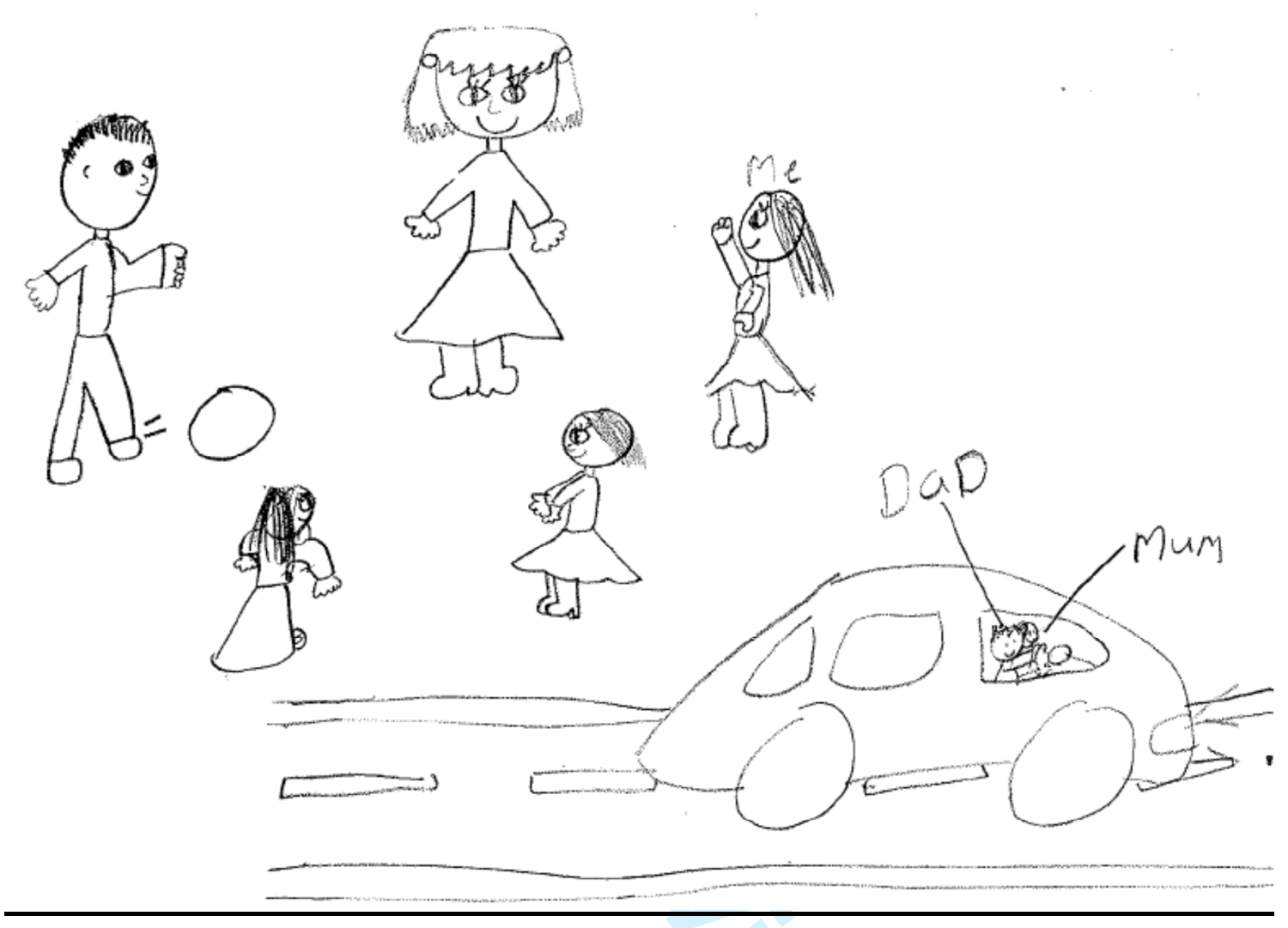

URL: http://mc.manuscriptcentral.com/epp 
Table 1: Pre and post-intervention themes

\begin{tabular}{|c|c|}
\hline Pre-intervention Theme & Description and rule of theme \\
\hline The need for being noticed & $\begin{array}{c}\text { References made to being noticed and } \\
\text { acknowledged by others }\end{array}$ \\
\hline $\begin{array}{c}\text { Difficulties in managing and } \\
\text { articulating emotions }\end{array}$ & $\begin{array}{c}\text { References made to anxieties about themselves } \\
\text { and/or significant factors in their lives }\end{array}$ \\
\hline Post-intervention Theme & Description and rule of theme \\
\hline & \\
\hline
\end{tabular}




\section{Introduction}

In the U.K there has been recent increased emphasis and growing appreciation by Government that academic standards cannot be raised simply through addressing the quality of teaching alone (e.g. Every Child Matters, DfES, 2003; Social and Emotional Aspects of Learning (SEAL)/Social and Emotional Aspects of Development (SEAD) Strategies, DfES, 2005; National Institute for Clinical Excellence (NICE) guidelines, 2008). As a result, a significant focus has been upon on the social and emotional well-being of children and young people and a need for early identification and prevention.

The school setting can present as a potential source of emotional well-being and resilience (DfES, 2003). Children spend a significant period of their lives at school, which provides essential opportunities for children to build consistent, trusting, secure relationships with adults, within which they can experience themselves positively, thus increasing their self-esteem and confidence. Secure attachments have been found to facilitate development of coping skills that promote optimum adjustment, which in turn, has been found to be an important protective factor for mental health in later childhood (Prior \& Glaser, 2006). The quality of these relationships further influences the child's cognitive and social development, as well as school engagement (Dobbs \& Arnold, 2009). Supportive teacher-child relationships have been shown to be more predictive of children's positive outcomes than are macro level factors such as programme policies and the quality of classroom environments (Mortiz-Rudasill \& Rimm-Kaufman, 2009). Negative teacher-child relationships have been linked to poor behavioural and academic outcomes for young children (Decker, Dona, \& Christenson, 2007; Garner \& Waajid, 2008).

Classroom interactions differ between securely and insecurely attached children with their teachers. Relative to their need for emotional support, insecurely attached children tend to seek to their teachers at a higher frequency than their securely attached class peers (Sroufe, 1988; Sroufe et al., 1999), and often attempt to garner attention, whether positive or negative (Belsky \& Fearson, 2002). Secure children accept the necessary support from their parents and teachers and seek help when 
they need it, openly communicating their distress when tasks demands become overwhelming (Bus \& van ljzendoorn, 1988).

Geddes (2006) highlighted that children bring their difficulties, frustrations, and uncertainties into the school context, with particular expectations of how their teacher will respond. The relationship between them and the teacher holds attachment significance. From an attachment perspective, the child's internal representations of parental sensitivity, availability and responsiveness inform expectations of relationships with peers and adults outside the family. Attachment-based interventions focussing on the quality of the teacher-pupil relationship is a significant yet much neglected factor for positive adaptation to school (Kennedy \& Kennedy, 2007).

Bowlby's (1969, 1973, 1980, 1988) work considered the formation of attachment, separation and loss, and focussed on the process of attachment of children to their caregivers. His theory of attachment has provided one framework for understanding how children view themselves in relation to the social world.

Bowlby (1980) described attachment behaviour as a child's proximity seeking to the attachment figure in the face of threat, with children developing adaptive patterns which may function to elicit caring, support and nourishment from a primary caregiver, typically their mother. In Bowlby's terms, a person who has experienced a secure attachment is likely to possess a representational model of attachment figure(s) as being available, responsive, and helpful. The person has a complementary model of himself as '... a potentially lovable and valuable person' (Bowlby, 1980, p.242) and is likely to 'approach the world with confidence and, when faced with potentially alarming situations, is likely to tackle them effectively or to seek help in doing so' (Bowlby, 1973, p.208). Infants whose needs have not been adequately met in this respect see the world as 'comfortless and unpredictable and they respond either by shrinking from it or doing battle with it' (Bowlby, 1973, p.208).

Mary Ainsworth's famous observations of infants and mothers (Ainsworth , Salter, \& Bell, 1970; Ainsworth, Blehar, Waters, \& Wall, 1978) found that children demonstrate a range of behaviours to achieve attachment defined as 'attachment behaviour'. This concurred with Bowlby's belief in the proximity seeking of the infant when 
activated by internal conditions such as hunger, cold or pain and by external conditions which are frightening, causing the infant to seek contact with an attachment figure.

Ainsworth observed how infants from 2 months onwards and increasingly through their first year, actively sought interaction. Ainsworth and Wittig (1969) 'Strange Situation' procedure measured the nature of the attachment bond between infant and attachment-figure. Different patterns of response to the mother at reunion were noted and four different attachment patterns identified:

- $\quad$ Secure

- Insecure-avoidant

- Insecure-resistant/ambivalent

- Insecure-disorganised/disorientated

The notion of an internal working model that controls the attachment behavioural systems and can be changed over time with alternative experiences, allows for a strong argument for the development of interventions which assist children in establishing more positive internal representations of themselves in relationship to others (Egeland, 2004).

The principal goal of this research was to explore the impact of an intervention, which focused upon building the attachment between primary-aged pupils with insecure attachment styles and an adult figure in school - the 'secure base' (Bowlby, 1988). There is accumulating evidence for the effectiveness of school-based preventive intervention programmes for a wide variety of childhood or adolescent problems, including aggressive or externalizing behaviours (Graham-Bermann, Lynch, Banyard, DeVoe \& Halabu, 2007; Shaw, Dishion, Supplee, Gardner \& Arnolds, 2006) and depressive symptoms (Horowitz \& Garber, 2006).

The 'Nurture group' is one intervention strategy based in schools, introduced in 1969 by Marjorie Boxall, an Educational Psychologist. Boxall understood the children's difficulties as the outcome of impoverished early nurturing, thus being unable to make trusting relationships with adults or to respond appropriately to other children. Nurture groups usually consist of 10-12 children, a class teacher and an assistant. 
The children assessed and monitored using the Boxall profile. Nurture groups have proven to be successful over the years in supporting pupil's social and emotional difficulties in schools (e.g., Cooper \& Tiknaz, 2005; Cooper \& Whitbread, 2007; SethSmith, Levi, Pratt, Fonagy \& Jaffey, 2010).

Waters' (2004b) 'Therapeutic Story Writing' intervention was designed to support pupils with emotional, behavioural and social difficulties at Key Stage 2. Using the medium of story writing, children's emotional issues are addressed, where the child explores and projects their own feelings onto different characters, scenes and plots, of which they are the creators. Water's (2004a) evaluation of the therapeutic story writing on a group of key stage 2 children found that they developed co-operative and trusting relationships with peers, support listening and speaking skills and foster interactive relationships between the teacher and group. Furthermore, Waters (2004b) stressed the importance of the teacher in providing an emotionally secure learning environment in which the child can feel safe enough to engage with their inner story.

\section{Rationale for current study}

The limited literature on the implementation of attachment-based interventions in the school context justified the need for the current research. It was hoped that by bridging the theory-into-practice gap, this research would address how attachment theories can inform educational consultations and intervention practices for children. This would support recent whole-school approaches and initiatives that have been implemented in schools and contribute to government initiatives.

This research was based within a mainstream school within the Local Educational Authority in which the researcher worked as an Educational Psychologist. Within their professional role, the researcher continuously met children and young people in schools who appeared to be displaying behaviours reflecting insecure attachments. The researcher consulted with staff who were often stressed and distraught as to the root of their pupil's difficulties. The researcher wanted to address these difficulties with an approach that would support both staff and enhance outcomes for the children. 
This research developed an intervention called the 'Secure Friendships Group' focussing on building pupil's attachment relationships in the school context. The group intervention involved primary aged pupils who displayed insecure attachment styles.

\begin{abstract}
AIMS
1. To demonstrate that children's insecure attachment behaviours can change positively
\end{abstract}

2. To demonstrate that school interventions can work/have a significant impact on withdrawn and passive children (not just referring to CAMHS)

3. To demonstrate how staff can benefit from knowledge of attachment theory (through teacher training, supervision, INSETS)

\title{
Method \\ Design of evaluation
}

The evaluation of this intervention study utilised a mixed methodology, with teachers rating the children's behaviours on standardised measures pre and post intervention complimented by semi-structured interviews with the children post intervention. This was a QUAL (qualitative)-quant (quantitative) design with the qualitative data taking precedence over the quantitative (Cresswell and Plano Clark, 2011). The researcher adopted a critical realist position in order to use a 'triangulation' strategy allowing a greater range of methods for data collection and from different sources. In this way it was hoped that the findings would be enriched thus further enhancing the rigour, breadth and richness of the research.

\section{Participants}

All participants attended a mixed mainstream primary school (School 'M') in an outer London borough. There were 264 students on role at the time with $1 \%$ of the children having a statement of Special Educational Need and a further $11 \%$ on School Action or School Action plus. School $M$ had a diverse population that included about a third of the students drawn from Black African backgrounds. The remaining two thirds were from white British, Turkish, Greek, Indian and Black 
Caribbean backgrounds. A sample of 6 children from school years $2-4$ (aged between 7 - 9 years) was derived using criterion sampling as the children needed to have met agreed criteria for attachment behaviour difficulties.

Inclusion Criteria for the Children:

- Living with a primary caregiver (maternal mother)

- English speaking

- No medical difficulties

- No specific learning difficulties

These children were selected on the basis that they were on the SEN Code of Practice School Action or School Action Plus. In particular, passive and withdrawn children who reflected characteristics of attachment difficulties were identified. These children were not receiving any additional support for their identified difficulties. This ensured that as far as possible any other support or interventions could not be attributed for any progress seen in the children post intervention. The final sample consisted of five children (1 white British, 2 black African and 2 black Caribbean) three of whom were boys. There was no control group in this research. All children were assigned pseudonyms to ensure confidentiality.

\section{Ethics}

Protection was ensured for all of the children during the research in that the methods and measures being used aimed to be non-pressuring, child-friendly, and were designed to avoid stress and distress. If stress and distress was experienced by the children, they were free to withdraw without stating a reason. This was communicated to the children by providing visual picture cards illustrating this choice. No child withdrew during the research.

All parents / carers and children gave informed consent. The welfare of participants was paramount throughout the research. The children were debriefed after data collection, during which the researcher explained how the research aimed to build the child's confidence, ability to make and keep friendships in school. Opportunities for children to ask the researcher questions were given at the end of the interviews.

\section{The Intervention}


The Secure Friendships group intervention ran weekly for approximately one and a half hours and took place over 10 weeks. The group was led by the researcher and a highly skilled learning support assistant (LSA), who was also a trained Learning Mentor. The LSA was extremely familiar with the school, staff and children (employed in the school for past 8 years) and was the 'Key attachment figure' in the school setting. During the Secure Friendships sessions, the researcher's main role was in supporting, facilitating and supervising the LSA. An adaptation of Waters (2004) therapeutic story telling was used during the intervention sessions. Books were purposefully selected in relation to their emotional content and events. By telling a story from the selected books, the children were given opportunities to use the metaphors in the stories to help them to deal with emotions and anxieties that they may not have been able to face or talk about directly.

Figure 1 Structure and sequence of each session.

\section{INSERT FIGURE 1}

\section{$\underline{\text { Measures }}$}

The following scales and measures were used pre and post intervention.

The Strengths and Difficulties Questionnaire (SDQ) (Goodman, 1997) is a brief behavioural screening questionnaire for 3-16 year old pupils focusing on 25 psychological attributes, 20 positive and 5 negative. These 25 items require the adult to mark one of the three boxes which reflect the child best, selecting from 'not true', 'somewhat true' or 'certainly true'. These are then scored using the scoring scale. The 25 items are divided between 5 scales:

- Emotional symptoms (5 items)

- Conduct problems (5 items)

- Hyperactivity (5 items)

- Peer relationships problems (5 items)

- Prosocial behaviour (5 items) 
The first four scale items scores are added together to generate a total difficulties score. The fifth scale generates a positive score.

The Boxall Profile (Bennathan and Boxall, 1998) provides a framework for the structured observation of children in the classroom. It involves the teacher scoring two checklists, the first of which reveals how the pupil progressed through the early learning processes and therefore how successfully they have organised their experiences and internalised controls. The second checklist identifies behaviours that inhibit or interfere with satisfactory involvement in school and suggests the origins of this behaviour.

The Behavioural Indicators of Self-Esteem (BIOS) (Burnett, 1998) is an instrument designed to provide teachers and SENCos in school with a means of observing and recording the frequency of behaviours indicative of poor / good selfesteem. It consists of 13 statements relating to a child's behaviour rated over several weeks. The teacher is required to select one of five options (ranging from 'never' to 'always') which they consider best describe an individual child's behaviour.

The Profile of Behaviour Based on Attachment Behaviour Characteristics (PBABC) (Geddes, 2009). The child's attachment behaviour is rated by the level of concern about the characteristic (separation behaviour), ranging from 1 (very little concern) to 5 (high level of concern). The total scores of attachment behaviour difficulties range from 10 to 50 . It is not a standardised tool but was developed in order to help those professionals working with children to focus on aspects of behaviour that have attachment significance and in turn inform understanding of what could be inhibiting a child's engagement.

Kinetic Family Drawing (KFD) (Burns \& Kaufman, 1970). The rationale for using drawings in this research was its typical perception as fun and non-threatening and it does not require literacy or verbal skills (DiCarlo, Gibbons, Kaminsky, Wright \& Stiles, 2000). Main, Kaplan and Cassidy (1985) were the first to suggest those children's drawings might be a rich way of capturing attachment representation, one of the reasons being that the nonverbal nature of drawing may free the child to express emotions and attitudes that are otherwise difficult to assess. KFD was used 
to gain a projective assessment of their attachment relationships. When administering the KFD, the researcher asked the child to 'draw everyone in the family doing something'. The child was provided with a plain piece of A4 paper and a pencil. KFD can be useful for discussions about activities and relationships with the family and open the opportunity for generating and refining hypotheses (Beaver, 2003).

\section{Semi-structured Interviews}

There are concerns about the ethical aspects of interviewing children (Brownlow \& O'Dell, 2002), which may be heightened when children with emotional and behavioural difficulties are involved, due to their perceived vulnerability (Cooper, 2006). During the interviews, a reflexive approach hoped to enable the children to give honest, authentic responses about aspects of themselves, their thoughts, their feelings and values.

\section{Data Collection Procedures Pre and Post Intervention}

The following outlines the data collection procedures for the evaluation of the intervention. The SDQs, BIOS's, Boxall profiles and PBABC were given to the children's class teachers to complete for the participating children one week before the intervention began (stage 1). Following this the 5 children were interviewed by the researcher, with each interview lasting approximately 45 minutes (stage 2). During this interview the children completed the KFD drawings. Stages 1 and 2 were repeated after the ten week intervention (becoming stages 3 and 4). The SDQ, BIOS and Boxall profiles were also administered to the children's teachers three months following the end of the intervention, to provide some measure of the longer term impact of the intervention on the children's observed behaviours (stage 5).

\section{Data analysis}

\section{Quantitative data analysis}

The Boxall profile's manual was used to score, analyse and summarise the children's behaviours. The PBABC were analysed through narratives of 
observations and scores both pre and post intervention. The children's scores on the SDQ, BIOS were compared pre and post-intervention using descriptive statistics.

Qualitative

The Kinetic Family Drawings were interpreted using the KFD guide and Beaver's work (2003).

The qualitative interview data was audio-recorded and transcribed verbatim. Thematic analysis was performed in relation to pre-determined themes (Hayes, 2000; Braun \& Clarke, 2006). The predetermined or deductive themes were extracted from key concepts of attachment theory.

\section{Findings}

As discussed earlier in this paper, the emphasis was on the qualitative data produced by the interviews with the children. In this section a brief outline of the quantitative data is reported in order to give the reader some context to the qualitative data analysis presented. The observational aspects of the Boxall Profile and the PBABC are discussed using a single case study. The remaining qualitative data (interviews and drawings) are presented via the children's narrative and the researcher's interpretation.

\section{Quantitative Findings}

The overall quantitative findings of the research indicated that for the group of children, the attachment-based intervention did have a positive impact on the children's behaviours. The behaviour rating sales and profiles provided evidence that the children had made progress in relation to their attachment behaviours and difficulties.

\section{SDQ Scores}

INSERT FIGURE 2 Total Scores for SDQ 
Total scores for the SDQ were calculated pre, post intervention and at follow up ten weeks later for all 5 children (Figure 2). The children's scores showed an overall decrease in their total difficulties scores following the intervention and at follow up.

\section{BIOS Scores}

INSERT FIGURE 3 Total scores for BIOS

Total scores for the BIOS were calculated pre, post intervention and at follow up ten weeks later for all 5 children (Figure 3). All five children's BIOS scores increased at follow-up ten weeks later. For two of the children, child $P$ and $T$, their scores increased steadily between pre, post and follow up to the intervention. For children $\mathrm{F}, \mathrm{J}$ and $\mathrm{J} 2$, there was a slight decrease in their BIOS scores at post intervention, with an increase greater than their initial pre intervention score at follow up.

\section{Profiles of Behaviour based on Attachment Behaviour characteristics}

Total scores for the Profiles of Behaviour were calculated pre, post intervention and at follow up ten weeks later for all 5 children (Figure 4). The overall pattern of PBABC showed a decrease in scores of attachment behaviour difficulties.

INSERT FIGURE 4 Total Scores for Profiles of Behaviour 


\section{Qualitative Findings}

Pre-intervention and Post-intervention Themes

Two themes are reported here both pre-intervention and post intervention, they were chosen to demonstrate the reported improvement in the children's relationships with their peers, family and teachers.

\section{INSERT TABLE 1}

\section{The need to be noticed (pre-intervention)}

This theme was identified in five children's accounts and was divided into two sub themes; social and emotional needs and adults acknowledging achievements.

Child F talked about how it was important that his teacher noticed that he was upset, (he had an argument with his friend) he needed someone to acknowledge that he was feeling sad. F did not feel that his emotion was being noticed by his teacher, and that this was something that he needed for him to feel better.

"...Yes it would be good if she saw me and then she comes over to me and tells me that she knows that I am angry and upset and maybe then she can talk to him and make it all o.k. and tell the horrible boys that they were horrible". C(F)

Another child talked about when she was feeling sad, the learning support assistant noticed and would often talk to her about her feelings. Child J2's comments reflect the importance of this in helping her to feel more confident:

"It does help me... when Mrs F tells me that I can come to her room and talk it does make me feel a lot better and I know then that I'll be alright and will be able to feel better for the rest of the day..." C(J2)

Adults acknowledging achievements via verbal comments, or other rewards were very important to these children. The need to be acknowledged for achievements by 
the token of a certificate was important to one child as it was something visual and concrete. Adults noticing and praising the children whilst they were behaving appropriately provided the message that they were in the minds of the adults.

\section{Difficulty in managing and articulating emotions (pre-intervention)}

This theme was further divided into 'Managing emotions' and 'Difficulty in articulating feelings'. The children reflected a need to be able to manage their emotions and in particular, access self-help strategies:

"I try to calm down...I count up to ten and then I try to breath out and then I calm down but sometimes it doesn't always work and I don't' feel better". $C(P)$

Child $\mathrm{J}$ also talked about how difficult it was to calm down following feeling upset, particularly if it was in relation to his favourite activity such as sport. $J$ was often observed by his teachers to be displaying anger and unable to manage this emotion:

"I don't know...[shrugs] I can't always kind of get better because I am upset and I don't know what I can do [shrugs]". C(J)

The children had limited abilities to articulate their feelings, even in light of their young age. It was as though the children were unaware of the social and emotional aspects of themselves and unsure of how to put their emotions into words in order to communicate them to an adult. Child $\mathrm{P}$ continuously looked down at her knees and couldn't express in words her sad feelings:

"I..[looks down at knees]...I...[shrugs]...she (referring to herself) might be sad and feel....[shrugs]...I don't know...I don't know....[looks down at knees]". C(P)

This brief narrative suggests that child $\mathrm{P}$ was an anxious child who had no or little experience expressing her anxieties and or emotions. 


\section{Forming a sense of belongingness (post intervention)}

'Being together as a group' and 'sense of security' were the two sub themes identified in the children's accounts. After the intervention the children's comments reflected a sense of belongingness; they felt more secure as a group not only within the Secure Friendships group but also in their own class groups:

"Like being in the Secure Friendships group, this one. I liked it and it was like this is my group and I come here every Wednesdays...and we all sit together and do all the things like news time and we share. I like it, it's really good". C(T)

Another child spoke about how he felt he was part of something special, similar to being in a family. The sense of sharing experiences and completing tasks together made him feel that they were all part of one unit. The children also expressed a feeling of safety and security both whilst within the intervention group and within themselves following the intervention. One child talked confidently about getting support from others:

"I can go in that room [pointed to adjacent room] and do my work and there are lots of things in there that I can use and I can ask Mrs F if I can use them...Ryan could do that on the island" (referring to a scenario in the interview question to a child 'Ryan' who was alone on an island and needed to seek help). C(J2)

J2 was now more confident that people in the school would help her if she approached them. She had an expectation that she would receive help, supporting the notion that her internal working model had shifted. This sense of security related to other figures in the school providing a 'secure base', a sense of predictability and security in which the child could feel a 'safe haven'.

\section{Quality of Friendships (post intervention)}

From pre-intervention analysis, there was more of a sense of the 'quantity' of friendships assuming greater importance than the 'quality' of the friendships. 
However, during post-intervention analysis, the children were able to articulate more about the quality of their friendships:

"S is my friend. I think I get along with her 'cos she really does listen to what I am saying and when I am feeling a bit upset and nervous she knows that I am and she helps me to get better." C(J2)

Friendship meant someone who was listening to what J2 was saying and acknowledging times when she was feeling upset and nervous. Another child reported on how special his friendship was with one child in particular:

"He's a really good friend to me 'cos he makes me laugh when I am feeling a bit sad ..... He says nice things to me and we play together all the time like we are special friends I think we are". C(F)

Child F was able to describe qualities of his friendship, "makes me laugh", "says nice things to me" and "play together".

The children's accounts also indicated a greater ability to manage conflicts with others. One child reported how following a fight with another child, he was able to manage this effectively by walking away:

"I sometimes have a fight with him [child] like we shout .... but then after I walk away from him it's better and I am better. It doesn't upset me and then I can stay on the green and not get into trouble [behaviour reward policy in school]..... But not always but now I can do this much much more". C(J)

Child J's comments referred to a strategy that he used in order to avoid conflict at the same time, $\mathrm{J}$ acknowledged that he was not always able to walking away to stay out of trouble.

\section{Case study of Kinetic Family Drawings of Child P}

P's two drawings are presented here to again illustrate the improvement in the children's relationship skills and experiences. 
INSERT FIGURE 5 (pre-intervention drawing)

\section{Main points interpreted from P's pre-intervention drawing:}

In P's KFD, she drew herself on one side of a tennis game net and her two sisters on the other side. They were all drawn as playing singles tennis game although $P$ was drawn by herself against the 2 'united' sisters. P's mum and dad can be seen in a car facing outwards, suggesting a sense of togetherness with one another but perhaps not with the children. These 'compartments' also suggested that the parents are functioning as a united unit within their relationships, but distinct from their children. It may also have suggested P's perception of her parents 'abandoning' her. P's brother is drawn at the top of the page and is watching television, indicating that he is an important family member. P's older sister is at the sink washing up, smiling and perhaps taking on an adult responsibility.

\section{INSERT FIGURE 6 (post intervention drawing)}

\section{Main points interpreted from P's post intervention drawing:}

All siblings are drawn playing football in a circle. P's brother is kicking a ball towards $P$ who is raising her hand saying 'me'. This suggests that her brother is noticing her and attending to her needs when she requests it. This resembles a more secure individual with their needs being met. All family members have smiles. Mum and dad are again in a car facing forwards, with road marks on the page, suggesting that 
they are confident in their directions and where they are going. Perhaps $P$ is also confident in their 'journey' and that she knows that they will return to her.

\section{Summary of differences for KFD pre and post-intervention for child P}

There appeared to be more of a sense of togetherness in P's post KFD and being part of a social group. The children were drawn 'united' in the post drawing and there was no net or barrier between them. The siblings were drawn to have a better 'sense' of themselves as they were drawn individually and independently. There also appeared to be an equal status for everyone and $\mathrm{P}$ a feeling of safety and security. Post intervention, P's drawing suggested that she was more confident that when her parents left her, they would return and meet her needs.

The overall findings of the research demonstrated that for this group of children, the attachment-based intervention did have a positive impact on the children's behaviours. The rich, descriptive qualitative data together with the behaviour rating sales and profiles provided evidence that the children had made progress in relation to their attachment behaviours and difficulties.

\section{Discussion}

The findings suggest that the IWMs of children with insecure attachments could be positively shifted and thus have an impact on the social and emotional behaviours of children. Howes (1999) stated: "Internal Working Models form within relationships and can, of course, be modified and 'disconfirmed' at any stage in the lifespan if individuals experience new, influential attachment relationships" (p.41). Secondly, the findings suggest that children can form some type of attachment to adult figures other than their primary caregiver. In this research, the learning mentor in the intervention group represented the key attachment figure, and therefore appeared to provide a much needed 'secure base' for the child. In Bion's (1993) theory of thinking, he claimed that anxiety needs to be contained by a significant other in order for the child to experience thinking and thus reduce their anxiety. The findings of this research supported the notion of containment within this relationship would help support the forming of a secure base. 


\section{Implications for EP Practice}

The practical implications of this paper focus on the need for developing individualised, attachment interventions with teachers in order to facilitate children's perceptions of the teacher and school context as a secure base. Vulnerable pupils and those at risk should be identified in the early years. This is particularly important for those children who are often quiet, withdrawn and overlooked. By early identification, these children may be prevented from becoming overly aroused, so that their anxiety levels do not increase to extremes levels which may later become problematic. The child's needs should be addressed holistically (Bronfenbrenner, 1979; Sameroff, Peck \& Eccles, 2004). Interventions should be comprehensive and systemic in their efforts to address the multiplicity of factors that contribute to the pupil's difficulties.

The school context provides key opportunities for children to form strong attachmentlike relationships with adults other than their parents, such as teachers or learning mentors. Few teachers or LSA's have sufficient training in psychological models such as attachment difficulties necessary to undertake work with these children. A whole-school approach can create a positive culture, focussing on shaping values, attitude and promoting trust, support and guidance for staff (Riley, 2010; Wetz, 2010). Gerda Hanko's (1985, 1990, 1995) 'Joint Problem Solving Workshop', reflects this approach, which consists of a work discussion group, for teaching staff, based on creating a 'safe' and 'secure thinking space' in which teachers and staff can present their experiences of challenging pupils. EPs can support schools in grasping and maximising these opportunities.

\section{Further Research}

Exploring how these children can use their 'altered' IWMs with their primary caregiver at home would provide deeper insight into their attachment behaviours and the more positive initiation of interactions between parent and child. The children's parent may be interviewed pre and post intervention to explore how the children's behaviours may have altered at home. This would provide greater evidence for whether the children's IWMs were significantly changed and generalised across multiple contexts. Further related research might also explore whether the social 
and emotional skills acquired in the intervention group are transferred back into the children's main classrooms.

Longitudinal studies and follow up gains could examine the impact of a longer attachment based intervention within the school context where children are involved over the course of six months to a year.

\section{Conclusion}

Intervening in the lives of children can be a challenging and dynamic process. This paper provides a strategy for intervention and understanding behavioural and emotional difficulties related to attachment. By providing a 'secure base' in the school context, within a small group experience, the children's difficulties were shown to be contained and managed. The research highlights the unique position of the EP in supporting staff in schools in implementing individual and group interventions, focussing on how children feel about themselves and their expectation of others. Efficacy of these interventions may be enhanced if they are combined with other interventions which target individual, dyadic, family, school and the community.

The core to Bowlby's attachment theory was the concept of early relationships between infants and their caregivers leading to the formation of mental representations of the self, others and the self in relation to others - the internal working model (Bowlby, 1969). The possibility that this working model can be positively shifted is an exciting and promising prospect. It is hoped that these encouraging research findings will inspire those working with children in schools to form attachment interventions for fragile and vulnerable children and ameliorate the impact of insecure attachments.

\section{References}

Ainsworth, M. (1989). Attachments beyond infancy. American Psychologist, 44(4), 709-716. 
Ainsworth, M. \& Wittig, D. (1969). Attachment and exploratory play behaviour of one year olds in a strange situation. In B. Foss (Ed.) Determinants of Infant Behaviour IV. London: Methuen.

Ainsworth, M., Blehar, M., Waters, E. \& Wall, S. (1978). Patterns of Attachment: A Psychological Study of the Strange Situation. Hillsdale, NJ: Lawrence Erlbaum.

Ainsworth, M., D. Salter, \& S. M. Bell. (1970). Attachment, Exploration, and Separation: Illustrated by the Behaviour of One-Year-Olds in a Strange Situation. Child Development 41, 49-67.

Beaver, R. (2003). Educational Psychology Casework: A Practical Guide. London: Jessica Kingsley Publishing.

Belsky, J. \& Fearson, R. M. (2002). Early attachment security, subsequent maternal sensitivity and later child development: Does continuity in development depend upon continuity of care giving? Attachment \& Human Development, 3, 361-387.

Bennathan, M. \& Boxall, M. (1998), The Boxall Profile: Handbook for Teachers, The Nurture Group Network.

Bion W.R. (1984). Second Thoughts: Selected Papers on Psychoanalysis. London: Maresfield Reprints.

Bion, W.R. (1993). Second thoughts. Northvale, NJ: Aronson.

Bowlby, J. (1969). Attachment and Loss, Volume 1: Attachment. London: Hogarth Press and the Institute of Psycho-Analysis.

Bowlby, J. (1973). Attachment and Loss, Volume 2: Separation: Anxiety and Anger. London: Hogarth Press and the Institute of Psycho-Analysis.

Bowlby, J. (1975). Attachment and Loss, Vol. 2. Harmondsworth: Penguin.

Bowlby, J. (1979). The Making and Breaking of Affectional Bonds. London: Brunner-Routledge.

Bowlby, J. (1980). Attachment and Loss, Volume 3: Loss: Sadness and Depression. London: Hogarth Press and the Institute of Pscyho-Analysis. 
Bowlby, J. (1984). 'Caring for the young: influences on development'. In R. Cohen, B. Cohler \& S. Weissman (Eds.) Parenthood: A Psychodynamic Perspective. New York: Guilford Press.

Bowlby, J. (1988). A Secure Base: Clinical Applications of Attachment Theory. London: Routledge.

Braun, V. \& Clarke, V. (2006). Using Thematic Analysis in Psychology. Qualitative research in Psychology, 3, 77-101.

Bronfenbrenner, U. (1979). The Ecology of Human Development: experiments by nature and design. Cambridge, MA: Harvard University Press.

Brownlow, C. \& O'Dell, L. (2002). Ethical Issues for Qualitative Research in On-line Communities. Disability \& Society, $\underline{17(6), 685-694}$

Burnett, P. C. (1998). Measuring behavioural indicators of self-esteem in the classroom. The Journal of Humanistic Education and Development, 37, 107-116.

Burns, R. C. \& Kaufman, M. D. (1970). Kinetic Family Drawings: An introduction to understanding children through kinetic drawings. London: Constable.

Bus, A.G., \& Van ljzendoorn, M. H. (1988). Mother-child interactions, attachment, and emergent literacy: A cross-sectional study. Child Development, 59, 1262-1272.

Cooper, P. (2006). Awareness, understanding and the promotion of educational engagement. Emotional and Behavioural Difficulties, 11(3), 151-153.

Cooper, P. \& Tiknaz, Y. (2005). Progress and challenge in Nurture Groups: evidence from three case studies. British Journal of Special Education, 32(4), 211222.

Cooper, P. \& Tiknaz, Y. (2007). Nurture Groups in School and at Home: Connecting with Children with Social, Emotional and Behavioural Difficulties. London: Jessica Kingsley Publishers.

Cooper, P. \& Whitebread, D. (2007) 'The Effectiveness of Nurture Groups: evidence from a National Research Study', Emotional and Behavioural Difficulties, 12(3), 17190. 
Creswell, J. W., \& Plano Clark, V. L. (2011). Designing and conducting mixed methods research (2nd ed.). Thousand Oaks, CA: Sage.

Decker, D.M., Dona, D.P. \& Christenson, S.L. (2007). Behaviourally at-risk African American students: The importance of student-teacher relationships for student outcomes. Journal of School Psychology, 45(1), 83-109.

Department for Education and Skills. (2003). Every Child Matters. London: DfES.

Department for Education and Skills. (2005). The Social and Emotional Aspects of Learning. London: DfES.

Dicarlo, M. A., Gibbons, J. L., Kaminsky, D.C., Wright, J. D. \& Stiles, D. A. (2000). Street children's drawings: Windows into their life circumstances and aspirations. International Social Work, 43, 107-120.

Egeland, B. (2004). Attachment-based intervention programs for young children. In R. E. Tremblay, R. G. Barr \& RdeV. Peters (Eds.) Encyclopaedia on Early Childhood Development. Montreal, Quebec: Centre of Excellence for Early Childhood Development, 1-7.

Garner, P. W. \& Waajid, B. (2008). Journal of Applied Developmental Psychology. Vol 29(2), 89-100.

Geddes, H. (2006). Attachment in the classroom. London: Worth Publishing Ltd.

Goodman, R. (1997). The Strengths and Difficulties Questionnaire: A research note. Journal of Child Psychology, Psychiatry, and Allied Disciplines, 38 (5), 581-586.

Graham-Bermann, S. A., Lynch, S., Banyard, V., DeVoe, E. \& Halabu, H. (2007). Community-based intervention for children exposed to intimate partner violence: An efficacy trial, Journal of Consulting and Clinical Psychology, 75(2), 199-209.

Grossmann, K. E., Grossmann, K. \& Waters, E. (2005). Attachment from infancy to adulthood: The major longitudinal studies. New York: Guilford Press.

Hanko, G. (1985, 1990, 1995) Special needs in ordinary classrooms: from staff support to staff development. Oxford: Blackwell. 
Horowitz, J.L., \& Garber, J. (2006). The prevention of depressive symptoms in children and adolescents: A meta-analytic review. Journal of Consulting and Clinical Psychology, 74, 401-415.

Howes, C. (1999). Attachment relationships in the context of multiple caregivers. In J. Cassidy \& P. R. Shaver (Eds.), Handbook of attachment (pp.671-687). New York: Milford Press.

Kennedy, J. H. \& Kennedy, C. E. (2007). Attachments Theory: Implications for School Psychology. Journal of Early Childhood and Infant Psychology, 3, 7-25.

Main, M., Kaplan, N., \& Cassidy, J. (1985). Security in infancy, childhood, and adulthood: A move to the level of representation. In I. Bretherton \& E. Waters (Eds.), Monographs of the Society for Research in Child Development, 50 (1-2),209, 66106.

Moritz Rudasil, K. \& Rimm-Kaufman, S. E. (2009). Teacher-child relationship quality: The roles of child temperament and teacher-child interactions. Early Childhood Research Quarterly, 24(2), 107-120.

National Institute for Health and Clinical Excellence (2008). Promoting children's social and emotional wellbeing in primary education. NICE public health guidance 12. London: Department of Health.

Prior, V. \& Glaser, D. (2006), Understanding Attachment and Attachment Disorders: Theory, Evidence and Practice: Child and Adolescent Mental Health Series. London: Jessica Kingsley

Riley, P. (2010). Attachment Theory and the Teacher-Student Relationship. London: Routledge.

Sameroff, A. J., Peck, S. C. \& Eccles, J. S. (2004). Changing ecological determinants of conduct problems from early adolescence to early adulthood. Development and psychopathology, 16(4), 873-96. 
Seth-Smith, F., Levi, N., Pratt, R., Fonagy, P. \& Jaffey, D. (2010). Do Nurture groups improve social, emotional and behavioural functioning of at risk children? Educational and Child Psychology, 27(1), 21-34.

Shaw, D.S., Dishion, T.J., Supplee, L., Gardner, F., Arnds, K. (2006). Randomized trial of a family-cantered approach to the prevention of early conduct problems: 2year effects of the family check-up in early childhood. Journal of Consulting and Clinical Psychology, 74,1-9

Social and Emotional Aspects of Learning (SEAL)/Social and Emotional Aspects of Development (SEAD) Strategies, DfES, 2007, 2005; DCSF, 2008.

Sroufe, L. A. (1988). The role infant-caregiver attachment in development. In J. Belsky \& T. Nezworski (Eds.), Clinical implications of attachment (pp. 18-40). Hillsdale, NJ: Erlbaum.

Sroufe, L. A., Carlson, E., Levey, A. \& Egeland, B. (1999). Implications of attachment for developmental psychopathology, 11, 1-13.

Sroufe, L. A., Egeland, B., Carlson, E. A. \& Collins, W. A. (2005). The development of the person: The Minnesota study of risk and adaptation from birth to adulthood. New York: Guilford Press.

Waters, T. (2004b). Writing Stories with Feeling: An evaluation of the impact of Therapeutic Story writing groups on Pupil's Learning. Pilot Evaluation Report for the Southeast Region Special Educational Needs Partnership.

Waters, T. (2004a). Therapeutic Story Writing. London: David Fulton.

Wetz, J. (2010). Is initial teacher training failing to meet the needs of all our young people? Berkshire: Centre for British Teachers (CfBT) Education Trust. 